
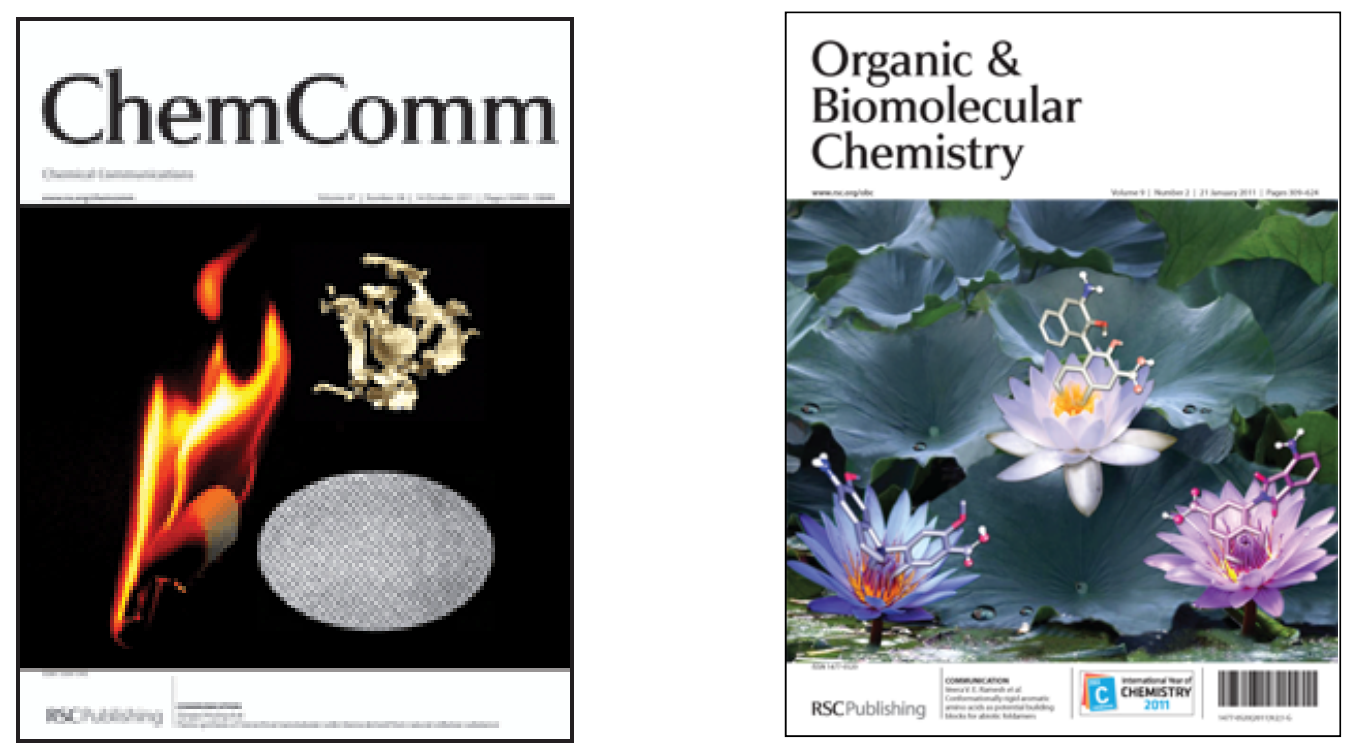

This article is part of the Organocatalysis web themed issue

Guest editors: Professors Keiji Maruoka, Hisashi Yamamoto, Liu-Zhu Gong and Benjamin List

All articles in this issue will be gathered together online at www.rsc.org/organocatalysis

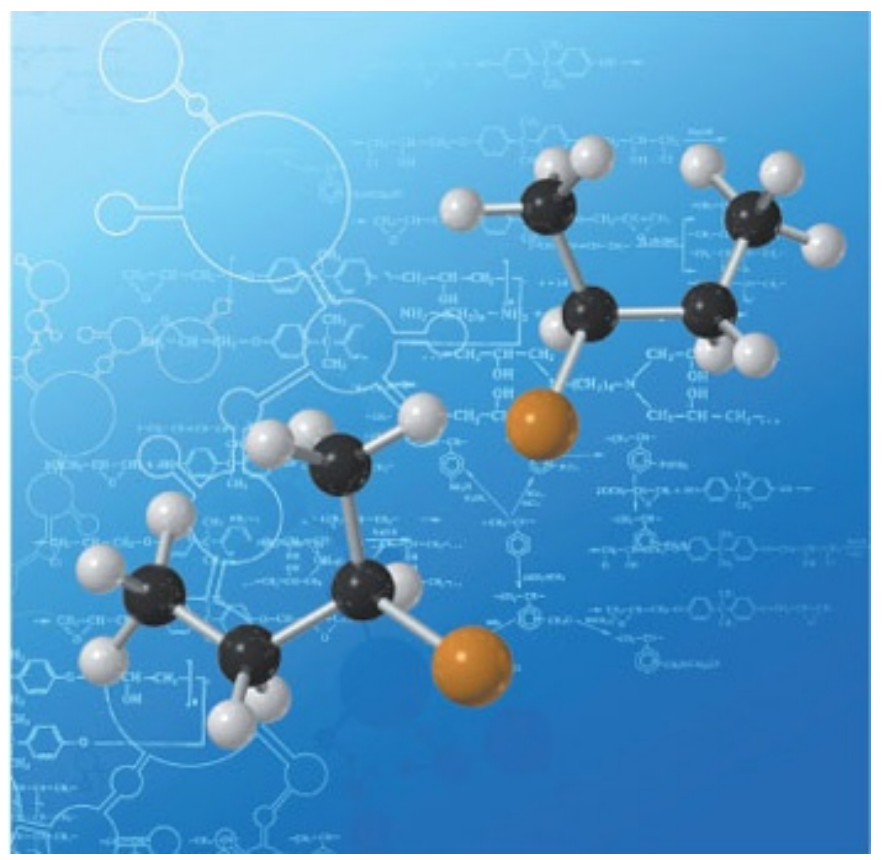




\title{
Kinetics and mechanism of organocatalytic aza-Michael additions: direct observation of enamine intermediates $\dagger \ddagger$
}

\author{
Sami Lakhdar, Mahiuddin Baidya and Herbert Mayr* \\ Received 17th February 2012, Accepted 13th March 2012 \\ DOI: $10.1039 / \mathrm{c} 2 \mathrm{cc} 31224 \mathrm{~g}$
}

The imidazoles $1 \mathrm{a}-\mathrm{g}$ add to the $\mathrm{CC}$-double bond of the iminium ion 2 with rate constants as predicted by the equation $\log \boldsymbol{k}=$ $s_{\mathrm{N}}(N+E)$. Unfavourable proton shifts from the imidazolium unit to the enamine fragment in the adduct 3 account for the failure of imidazoles to take part in iminium-activated azaMichael additions to enals.

Since MacMillan's pioneering work in $2000,{ }^{1}$ the so-called iminium activation has become one of the most attractive methods in asymmetric synthesis. ${ }^{2}$ In his seminal paper, MacMillan showed that $\alpha, \beta$-unsaturated aldehydes can be activated by the addition of catalytic amounts of chiral secondary amines; the initially generated iminium ions undergo fast Diels-Alder reactions with dienes to give cycloadducts, which release the chiral catalyst upon hydrolysis. ${ }^{1}$ By using this strategy it has become possible to realise a large variety of enantioselective organic reactions. ${ }^{3}$

In 2007, Jørgensen et $a l^{4}$ and Vicario et $a l^{5}$ independently reported the first enantioselective aza-Michael additions of nitrogen heterocycles to aliphatic unsaturated aldehydes (Scheme 1), using diarylprolinol silyl ethers or imidazolidinones as catalysts. ${ }^{6}$

While these reactions proceeded readily with tetrazoles and triazoles, they generally failed with imidazoles and benzimidazoles.

Only 4,5-dicyano-imidazole was found to react with moderate yield and low enantioselectivity with aliphatic enals utilizing MacMillan's second generation imidazolidinone as a catalyst. ${ }^{5}$ Under the same conditions, the parent imidazole 1c gave only traces of the product.

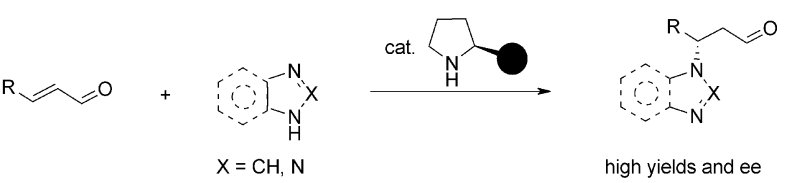

Scheme 1 Aza-Michael additions of $N$-heterocycles to enals catalysed by chiral secondary amines. ${ }^{4-6}$

Department Chemie, Ludwig-Maximilians-Universität München, Butenandtstr. 5-13 (Haus F), 81377 München, Germany.

E-mail: Herbert.Mayr@cup.uni-muenchen.de;

Fax: + 4989218077717

$\uparrow$ This article is part of the joint ChemComm-Organic \& Biomolecular Chemistry 'Organocatalysis' web themed issue.

\pm Electronic supplementary information (ESI) available: Details of the kinetic experiments, synthetic procedures and product characterisation. See DOI: $10.1039 / \mathrm{c} 2 \mathrm{cc} 31224 \mathrm{~g}$
We now report the kinetics and mechanism of the reactions of imidazoles with the iminium ion $\mathbf{2}$ and rationalise why imidazoles, in contrast to triazoles and tetrazoles, do not undergo organocatalytic aza-Michael additions.

In previous work we have shown that the rates of the reactions of carbocations and Michael acceptors with $n, \pi$, and $\sigma$ nucleophiles can be described by eqn (1), ${ }^{7}$ where $k_{2}$ is a second-order rate constant in $\mathrm{M}^{-1} \mathrm{~s}^{-1}, s_{\mathrm{N}}$ is a nucleophilespecific sensitivity parameter, $N$ is a nucleophilicity parameter, and $E$ is an electrophilicity parameter.

$$
\log k_{2}\left(20{ }^{\circ} \mathrm{C}\right)=s_{\mathrm{N}}(N+E)
$$

Using the known reactivity parameters $N$ and $s_{\mathrm{N}}$ of the imidazoles $\mathbf{1} \mathbf{a}-\mathbf{g}^{8}$ (Table 1) and the electrophilicity parameter of the cinnamaldehyde-derived iminium ion $\mathbf{2}^{9}(E=-7.37)$, we had calculated second-order rate constants of 300-3000 $\mathrm{M}^{-1} \mathrm{~s}^{-1}$ by eqn (1) indicating that the reactions of $\mathbf{2}$ with $\mathbf{1} \mathbf{a}-\mathbf{g}$ should proceed readily.

Accordingly, treatment of the iminium salt $\mathbf{2}-\mathbf{P F}_{\mathbf{6}}$ with 4 equivalents of imidazole 1c leads to the formation of the enamine 3c, which bears a protonated imidazole ring. Adduct 3c, which incorporates two stereocenters, was formed as a $1: 1$ mixture of two diastereoisomers, as revealed by ${ }^{1} \mathrm{H}$ and ${ }^{13} \mathrm{C}$

Table 1 Nucleophile-specific reactivity parameters $N$ and $s_{\mathrm{N}}$ for azoles in acetonitrile ${ }^{8}$

\begin{tabular}{|c|c|c|c|c|c|}
\hline Azoles & $N$ & $s_{\mathrm{N}}$ & Azoles & $N$ & $s_{\mathrm{N}}$ \\
\hline 1a & $10.50^{a}$ & $0.79^{a}$ & 1e & 11.74 & 0.76 \\
\hline $1 b$ & 11.43 & 0.79 & 1f & 11.79 & 0.77 \\
\hline $1 c$ & 11.47 & 0.79 & $1 \mathrm{~g}$ & 11.90 & 0.73 \\
\hline 1d & 11.51 & 0.84 & & & \\
\hline
\end{tabular}

${ }^{a} N$ and $s_{\mathrm{N}}$ refer to DMSO, as 4-(dimethylamino)pyridine was reported to have identical reactivity parameters in DMSO and acetonitrile $(\Delta N=$ $0.15)^{10}$ the variation of solvent does not affect the analysis in Table 2. 


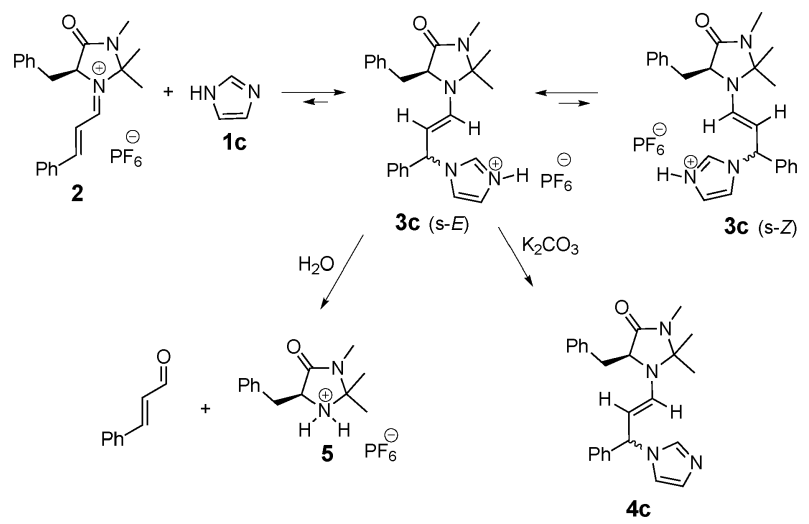

Scheme 2

NMR spectroscopy. NOE analysis showed the preference of the (s-E)-conformation of the $\mathrm{C}\left(\mathrm{sp}^{2}\right)-\mathrm{N}$ bond in both diastereoisomers as depicted in Scheme 2. As kinetically controlled additions of nucleophiles to $\mathbf{2}$ often proceed with high diastereoselectivity, the formation of $\mathbf{3 c}$ as a $1: 1$ mixture of diastereomers may either be explained by a reversible reaction of the iminium ion $\mathbf{2}$ with the imidazole $\mathbf{1 c}$ or by deprotonation of the imidazolidinone moiety in the intermediate iminium ion in the $\alpha$-position to the carbonyl group, as suggested by Seebach et al. ${ }^{11}$ The latter mechanism can be excluded under the conditions of this work because we have recovered the enantiopure imidazolidinone $\mathbf{5}$ after hydrolysis of $\mathbf{3 c}$, confirming that the configuration of the asymmetric center of the imidazolidinone 5 has not been affected.

In acetonitrile solution, the enamine intermediates $\mathbf{3 c}$ (or $\mathbf{4 c}$ in the presence of excess imidazole) are stable for more than 8 hours but decompose during several days. Addition of water to the enamine $\mathbf{3 c}$ leads to the formation of cinnamaldehyde. However, stirring of a solution of $\mathbf{3} \mathbf{c}-\mathbf{P F}_{\mathbf{6}}$ in $\mathrm{CD}_{3} \mathrm{CN}$ with dry $\mathrm{K}_{2} \mathrm{CO}_{3}$ led to the formation of $\mathbf{4 c}$, which was characterised by ${ }^{1} \mathrm{H}$ and ${ }^{13} \mathrm{C}$ NMR spectroscopy (see ESI $\ddagger$ ). ${ }^{12,13}$

Jørgensen's DFT calculations on the organocatalytic conjugate addition of 1,2,4-triazole to $\alpha, \beta$-unsaturated aldehydes showed that the addition of the triazole to the iminium ion is followed by a water-assisted proton transfer from the triazolium ring to the enamine as depicted in Scheme $3{ }^{4}$ In the case of the reactions of the azoles $\mathbf{1}$ with the iminium ion $\mathbf{2}$, the enamines $\mathbf{3}$ or their conjugate bases $\mathbf{4}$ were observed by NMR spectroscopy, and we did not observe an analogous proton transfer which may be explained by the lower acidities of the imidazolium ions compared to triazolium ions.

The different UV-absorbances of the iminium ions $\mathbf{2}$ and the adducts $\mathbf{3}$ allowed us to follow the kinetics of the reactions of $\mathbf{2}$ with the azoles $\mathbf{1 a}-\mathbf{g}$ photometrically at the absorption maximum of the iminium ion $2(370 \mathrm{~nm})$. All kinetic experiments were performed under first-order conditions using a high excess of the

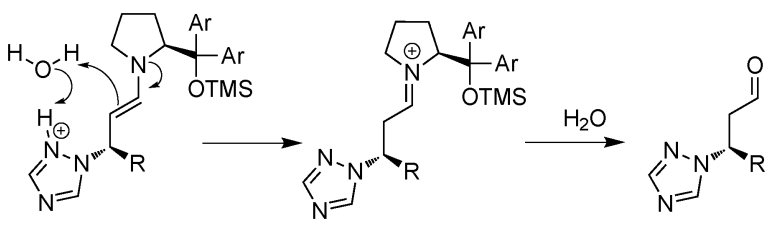

Scheme 3

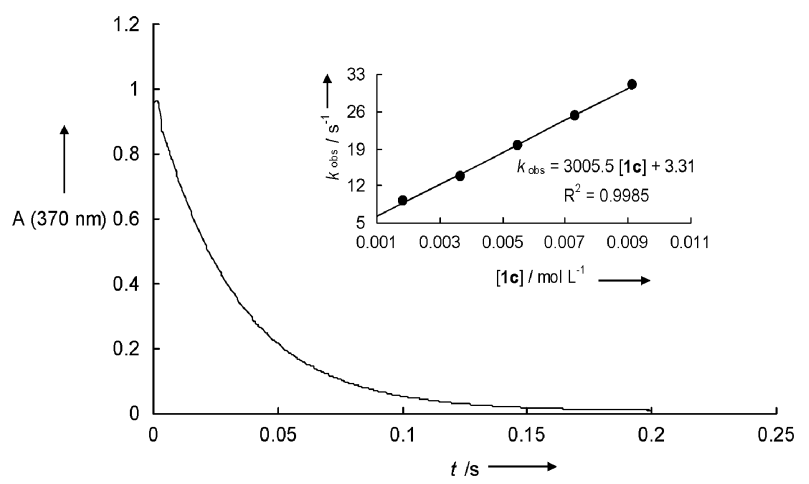

Fig. 1 Exponential decay of the absorbance at $370 \mathrm{~nm}$ during the reaction of 2-OTf $\left(5.10 \times 10^{-5} \mathrm{M}\right)$ with imidazole $1 \mathrm{c}\left(5.47 \times 10^{-3} \mathrm{M}\right)$. Inset: determination of the second-order rate constant $k_{2}$ from the dependence of the first-order rate constant $k_{\mathrm{obs}}$ on the concentration of imidazole $1 \mathrm{c}\left(20^{\circ} \mathrm{C}\right.$ in $\left.\mathrm{CH}_{3} \mathrm{CN}\right)$.

nucleophiles 1a-g. From the exponential decays of the UVabsorbances of the electrophile $\mathbf{2}$, the first-order rate constants $k_{\text {obs }}$ were obtained.

Plots of $k_{\mathrm{obs}}\left(\mathrm{s}^{-1}\right)$ against the concentrations of the nucleophiles 1a-g were linear (Fig. 1) and their slopes gave the second-order rate constants $k_{2}\left(\mathrm{M}^{-1} \mathrm{~s}^{-1}\right)$ which are summarised in Table 2.

The second-order rate constants thus obtained (Table 2) have been compared with those calculated by eqn (1) from the electrophilicity parameter $E=-7.37$ of the iminium ion $\mathbf{2}^{9}$ and the $N$ and $s_{\mathrm{N}}$ parameters of the azoles. ${ }^{8}$ Table 2 shows that all calculated $\left(k_{\text {calc }}\right)$ and experimental rate constants $\left(k_{\text {exp }}\right)$ match within a factor of two. This good agreement is impressive, as $E(\mathbf{2})$ has been derived from reactions with C-nucleophiles and $N$ and $s_{\mathrm{N}}$ for the azoles $\mathbf{1 a}-\mathbf{g}$ have been derived from their reactions with benzhydrylium ions. ${ }^{7}$

Some of the reactions of the iminium ion $\mathbf{2}$ with imidazoles proceeded incompletely, and for the reactions with $\mathbf{1 b}$ and $\mathbf{1 g}$ the equilibrium constants $K$ (Scheme 4 ) have been determined photometrically as described in the ESI. $\ddagger$

Table 2 Comparison of experimental $\left(k_{\exp }\right)$ and calculated rate constants $\left(k_{\text {calc, }}\right.$, using eqn (1)) for the reactions of the azoles $\mathbf{1 a - g}$ with the iminium ion $2(E=-7.37)$ in $\mathrm{CH}_{3} \mathrm{CN}$ at $20{ }^{\circ} \mathrm{C}$

\begin{tabular}{llll}
\hline Azoles & $k_{\exp } / \mathrm{M}^{-1} \mathrm{~s}^{-1}$ & $k_{\text {calc }} / \mathrm{M}^{-1} \mathrm{~s}^{-1}$ & $k_{\text {exp }} / k_{\text {calc }}$ \\
\hline $\mathbf{1 a}$ & $2.75 \times 10^{2}$ & $2.97 \times 10^{2}$ & 0.93 \\
$\mathbf{1 b}$ & $2.88 \times 10^{3}$ & $1.61 \times 10^{3}$ & 1.8 \\
$\mathbf{1 c}$ & $3.01 \times 10^{3}$ & $1.73 \times 10^{3}$ & 1.7 \\
$\mathbf{1 d}$ & $3.00 \times 10^{3}$ & $3.00 \times 10^{3}$ & 1.0 \\
1e & $2.84 \times 10^{3}$ & $2.10 \times 10^{3}$ & 1.4 \\
$\mathbf{1 f}$ & $4.62 \times 10^{3}$ & $2.53 \times 10^{3}$ & 1.8 \\
$\mathbf{1 g}$ & $4.15 \times 10^{3}$ & $2.03 \times 10^{3}$ & 2.0 \\
\hline
\end{tabular}
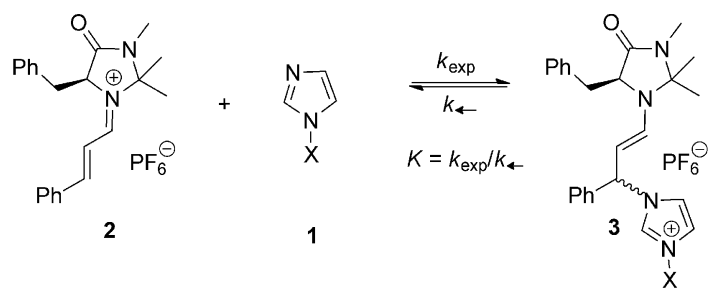

Scheme 4 Reversible additions of the imidazoles $\mathbf{1 b}$ and $\mathbf{1 g}$ to the iminium ion 2 in $\mathrm{CH}_{3} \mathrm{CN}$. 
Table 3 Equilibrium constants $(K)$ for the reactions of azoles $\mathbf{1 b}$ and $1 \mathrm{~g}$ with the iminium ion 2 (counterion $\mathrm{PF}_{6}{ }^{-}$) in $\mathrm{CH}_{3} \mathrm{CN}$ at $20{ }^{\circ} \mathrm{C}$

\begin{tabular}{lllllc}
\hline Azoles & $K / \mathrm{M}^{-1}$ & $\begin{array}{l}\Delta G^{\neq} / \\
\mathrm{kJ} \mathrm{mol}^{-1}\end{array}$ & $\begin{array}{l}\Delta G^{0} / \\
\mathrm{kJ} \mathrm{mol}\end{array}$ & $\begin{array}{l}\Delta G_{0}^{\neq} / \\
\mathrm{kJ} \mathrm{mol}\end{array}$ & $k_{\leftarrow} / \mathrm{s}^{-1}$ \\
\hline $\mathbf{1 b}$ & $1.61 \times 10^{3}$ & 52.3 & -18.0 & 61.0 & 1.79 \\
$\mathbf{1 g}$ & $1.84 \times 10^{2}$ & 51.4 & -12.7 & 57.6 & 22.6 \\
\hline
\end{tabular}

Table 3 shows that 1-(trimethylsilyl)-imidazole $\mathbf{1 b}$, which is 1.4 times less nucleophilic than 1-methylimidazole $\mathbf{1 g}$ (Table 2), is a nine-fold stronger Lewis base than $\mathbf{1 g}$. Substitution of the rate and equilibrium constants into the Marcus equation (2) yields the intrinsic barriers $\Delta G_{0}^{\neq}$, which are defined as the activation energies of processes with $\Delta G^{0}=0 .{ }^{14}$

$$
\Delta G^{\neq}=\Delta G_{0}^{\neq}+0.5 \Delta G^{0}+\left(\left(\Delta G^{0}\right)^{2} / 16 \Delta G_{0}^{\neq}\right)
$$

Remarkably, the intrinsic barrier for the addition of the azole $1 \mathrm{~g}$ to the iminium ion 2 is about $10 \mathrm{~kJ} \mathrm{~mol}^{-1}$ lower than that for its reaction with diarylcarbenium ions. ${ }^{8}$ This difference reflects that more reorganisation energy is needed for the reactions of nucleophiles with diarylcarbenium ions than with unsaturated iminium ions due to the more extensive delocalization of the positive charge in diarylcarbenium ions.

In conclusion, we have shown that the reactions of the iminium ion $\mathbf{2}$ with imidazoles proceed readily with formation of stable enamines which have been fully characterised by NMR spectroscopy. The failure of the azoles $\mathbf{1 a}-\mathbf{g}$ to act as nucleophiles in iminium-activated processes is rationalised by the low acidities of the initially generated azolium species which do not undergo proton shifts. The rate constants determined for the reactions of the iminium ion $\mathbf{2}$ with the azoles 1a-g are in good agreement with those calculated by eqn (1), showing the suitability of the benzhydrylium-based reactivity parameters $N$ and $s_{\mathrm{N}}$ for predicting reactivities toward iminium ions.

We thank Dr Armin R. Ofial and Biplab Maji for helpful discussions and the Deutsche Forschungsgemeinschaft (SFB 749) for generous support.

\section{Notes and references}

1 K. A. Ahrendt, C. J. Borths and D. W. C. MacMillan, J. Am. Chem. Soc., 2000, 122, 4243.
2 For reviews on asymmetric iminium catalysis, see: (a) A. Berkessel and H. Gröger, Asymmetric Organocatalysis, Wiley-VCH, Weinheim, 2005; (b) G. Lelais and D. W. C. MacMillan, Aldrichimica Acta, 2006, 39, 79; (c) A. Erkkilä, I. Majander and P. M. Pihko, Chem. Rev., 2007, 107, 5416; (d) S. B. Tsogoeva, Eur. J. Org. Chem., 2007, 1701; (e) D. Almași, D. A. Alonso and C. Nájera, Tetrahedron: Asymmetry, 2007, 18, 299; (f) J. Seayad and B. List, Org. Biomol. Chem., 2005, 3, 719; $(g)$ B. List and J.-W. Yang, Science, 2006, 313, 1584; (h) B. List, Chem. Commun., 2006, 819.

3 (a) D. W. C. MacMillan, Nature, 2008, 455, 304; (b) J. B. Brazier and N. C. O. Tomkinsson, Top. Curr. Chem., 2010, 291, 281.

4 P. Diner, M. Nielsen, M. Marigo and K. A. Jørgensen, Angew. Chem., 2007, 119, 2029 (Angew. Chem., Int. Ed., 2007, 46, 1983).

5 U. Uria, J. L. Vicario, D. Badia and L. Carrillo, Chem. Commun., 2007, 2509.

6 For a comprehensive review on organocatalytic aza-Michael additions, see: D. Enders, C. Wang and J. X. Liebich, Chem.-Eur. J., 2009, 15, 11058.

7 (a) H. Mayr and M. Patz, Angew. Chem., 1994, 106, 990 (Angew. Chem., Int. Ed. Engl., 1994, 33, 938); (b) H. Mayr, T. Bug, M. F. Gotta, N. Hering, B. Irrgang, B. Janker, B. Kempf, R. Loos, A. R. Ofial, G. Remennikov and H. Schimmel, J. Am. Chem. Soc., 2001, 123, 9500; (c) H. Mayr, B. Kempf and A. R. Ofial, Acc. Chem. Res., 2003, 36, 66; (d) H. Mayr and A. R. Ofial, Pure Appl. Chem., 2005, 77, 1807; (e) H. Mayr and A. R. Ofial, J. Phys. Org. Chem., 2008, 21, 584.

8 M. Baidya, F. Brotzel and H. Mayr, Org. Biomol. Chem., 2010, 8, 1929.

9 (a) S. Lakhdar, T. Tokuyasu and H. Mayr, Angew. Chem., 2008, 120, 8851 (Angew. Chem., Int. Ed., 2008, 47, 8723); (b) S. Lakhdar, J. Ammer and H. Mayr, Angew. Chem., 2011, 123, 10127 (Angew. Chem., Int. Ed., 2011, 50, 9953).

10 F. Brotzel, B. Kempf, T. Singer, H. Zipse and H. Mayr, Chem.Eur. J., 2007, 13, 336-345.

11 D. Seebach, U. Grošelj, D. M. Badine, W. B. Schweizer and A. K. Beck, Helv. Chim. Acta, 2008, 91, 1999.

12 For recent reports on the isolation of enamines derived from chiral amines, see: (a) U. Grošelj, D. Seebach, D. M. Badine, W. B. Schweizer, A. K. Beck, I. Krossing, P. Klose, Y. Hayashi and T. Uchimaru, Helv. Chim. Acta, 2009, 92, 1225; (b) P. Dominguez de Maria, P. Bracco, L. Fernando Castelhano and G. Bargeman, ACS Catal., 2011, 1, 70; (c) K. P. Komisarska, M. Benohoud, H. Ishikawa, D. Seebach and Y. Hayashi, Helv. Chim. Acta, 2011, 94, 719.

13 For recent reports on the NMR spectroscopic detection of chiral enamines as reaction intermediates see: (a) M. B. Schmid, K. Zeitler and R. M. Gschwind, J. Am. Chem. Soc., 2011, 133, 7065; (b) M. B. Schmid, K. Zeitler and R. M. Gschwind, Angew. Chem., 2010, 122, 5117 (Angew. Chem., Int. Ed., 2010, 49, 4997); (c) M. B. Schmid, K. Zeitler and R. M. Gschwind, Chem. Sci., 2011, 2, 1793.

14 (a) R. A. Marcus, J. Phys. Chem., 1968, 72, 891; (b) W. J. Albery, Annu. Rev. Phys. Chem., 1980, 31, 227. 